\title{
No commitment to the truth
}

\section{Anna-Maria A. Eder ${ }^{1}$}

Received: 2 May 2019 / Accepted: 23 December 2019 / Published online: 12 February 2020

(c) The Author(s) 2020

\begin{abstract}
On an evidentialist position, it is epistemically rational for us to believe propositions that are (stably) supported by our total evidence. We are epistemically permitted to believe such propositions, and perhaps even ought to do so. Epistemic rationality is normative. One popular way to explain the normativity appeals to epistemic teleology. The primary aim of this article is to argue that appeals to epistemic teleology do not support that we ought to believe what is rational to believe, only that we are permitted to do so. In arguing for that, I defend an epistemic teleological position that is radical in nature. It involves no commitment to aiming at the truth. I conclude by dispelling some worries that have been raised about my position.
\end{abstract}

Keywords Epistemic teleology · Epistemic normativity · Epistemic rationality · Value of truth

\section{Introduction}

\subsection{Evidentialism and the normativity of epistemic rationality}

Given the body of evidence that climate scientists have collected, there is no doubt that it is epistemically rational for the scientists to believe that there is human-induced climate change. If you agree, this might be because you accept something like the following evidentialist position:

The present article is the sequel to my article "Epistemic Teleology for Evidentialists".

\footnotetext{
$凶$ Anna-Maria A. Eder

eder.anna-maria@uni-koeln.de

1 University of Cologne, Cologne, Germany
} 
Evidentialism It is epistemically rational for an agent $s$ to believe a proposition $p$ given $s$ 's total evidence $e_{s}$ just in case $e_{s}$ supports $p .^{1}$

Evidentialism is popular but does not hold in general; it therefore needs revision. ${ }^{2}$ If evidential support is relevant for whether believing a proposition is epistemically rational, then it should not disappear as soon as one believes the proposition. Mere evidential support does not suffice alone: the evidential support for the proposition has to be stable - at least in the weak sense that does not allow for the support disappearing when one believes the proposition. By adding that the support has to be stable, one excludes that it is rational to believe propositions that are supported by the total evidence but are no longer supported the instant one believes them. Such propositions cannot be stably supported by the total evidence. Accordingly, I propose to replace Evidentialism by Evidentialism ${ }^{S}$ : $\begin{aligned} \text { Evidentialism }^{S} & \text { It is epistemically rational for an agent } s \text { to believe a proposition } p \\ & \text { given } s \text { 's total evidence } e_{s} \text { just in case } e_{s} \text { stably supports } p \text {. }\end{aligned}$

Given the understanding of stable evidential support in question here, our total evidence stably supports that there is human-induced climate change. Given Evidentialism ${ }^{S}$, it is thus epistemically rational to believe that there is human-induced climate change. However, it is not only epistemically rational for us to believe that there is humaninduced climate change. From an epistemic perspective, it also seems to be permitted to believe it. The following position is commonly accepted:

Permitted If it is epistemically rational for an agent $s$ to believe a proposition $p$ given $s$ 's total evidence $e_{s}$, then $s$ is epistemically permitted to believe $p$ given $e_{s}$.

Moreover, it might even be that we epistemically ought to believe that there is humaninduced climate change. In addition to Permitted, the following might also hold:

\footnotetext{
${ }^{1}$ I am concerned with propositional rationality with respect to a single proposition-as opposed to both doxastic rationality and rationality with respect to a set of propositions. Here, I understand the distinction between propositional and doxastic rationality analogously to the well-established distinction between propositional and doxastic justification. (Smithies (2016) and Williamson (2017) apply the distinction to rationality as well.)

2 That Evidentialism is in need of revision becomes apparent when one considers cases in which the proposition that is supported by the total evidence is no longer supported the instant one believes the proposition. In such cases the proposition is supported by the total evidence and according to Evidentialism it is rational to believe the proposition, but one loses the support simply by believing the proposition in question. For instance, consider cases where the total evidence supports that one's performance in some task will be successful, but by believing this one becomes overconfident and loses the support. Although it is rational for one to believe that one's performance will be successful, the belief is not rational because one loses the evidential support by holding the belief. (For discussions of such cases and the challenge they pose for Evidentialism, see among others (Conee 1994; Odegard 1993). On the basis of such cases, I argue in detail for Evidentialism ${ }^{S}$ in the prequel of this article.) There are at least two ways to revise Evidentialism to avoid such problems. One can restrict Evidentialism to propositions that do not lose their support as soon as one believes them, or one can add a further condition to evidential support. Instead restricting the scope, which would in effect be to ignore the problem, I opt for the latter option.
} 
Ought If it is epistemically rational for an agent $s$ to believe a proposition $p$ given $s$ 's total evidence $e_{s}$, then $s$ epistemically ought to believe $p$ given $e_{s} .{ }^{3,4}$

It is commonly assumed that epistemic rationality is epistemically normative and that Permitted or even Ought holds. The normativity may be merely pro tanto and, in particular situations, the normativity might be defeated or trumped by other forms of normativity, for instance by all-things-considered or ethical normativity. However, rationality is commonly considered to be epistemically normative. Different approaches are adopted in arguing for the epistemic normativity of epistemic rationality. Some epistemologists think that the normativity is based on some kind of reasons that pertain to the case in question. Others adopt an epistemic teleological position and think that the epistemic normativity of epistemic rationality is based on the conduciveness to a valuable epistemic end. In this article, I concentrate on the latter option and take it as a staring point.

To be more precise, I focus on direct epistemic teleological positions that agree on the following ${ }^{5}$ :

\begin{abstract}
${ }^{3}$ Epistemologists who see epistemic rationality as going hand-in-hand with what we (epistemically) ought to believe include Brössel et al. (2013) and Kelly (2007, 2003). Nelson (2010) seems to have a principle such as Ought in mind when he argues against positive epistemic duties. One might be tempted to constrain the following Ought by making it dependent on the subjective intellectual interests of the agent or, alternatively, on whether they form any attitude at all towards the proposition in question (and, indeed, a referee of this article seems tempted to do so). Since many discussants in the literature - such as those mentioned abovedo not make epistemic norms or epistemic normativity depend on subjective intellectual interests or whether the agent forms an attitude towards the proposition, I address the unrelativised Ought. I leave it for another occasion to investigate relativised versions of it. Section 4 gives hints concerning which relativised versions of Ought might hold.
\end{abstract}

${ }^{4}$ Some epistemologists might reject Ought or even the weaker Permitted right away. They might, for instance, think that it is always rational for one to believe a logical truth, but that there are logical truths that are so complex that one is never able to form or ground one's belief in them in an adequate way, or that one has defeating higher-order evidence that prevents one from forming or grounding one's belief in an adequate way (see, e.g., Smithies 2015). They could argue that since one is not able to form or ground one's belief in these logical truths in an adequate way one is not even permitted to believe them. Other epistemologists might think that it is sometimes rational to believe a Moore-paradoxical proposition such as of the form ' $p$ and I believe $\neg p$ ', but that one can never form or ground one's belief in such a proposition in an adequate way (see, e.g., Smithies 2016). Thus, they could argue that one is not permitted to believe them. The same objections speak against Ought since it is stronger. Such objections include the implicit assumption that it can be (propositionally) rational for an agent to believe a proposition although the agent is not able to form the respective (doxastically) rational belief, for instance, by grounding it adequately. One can avoid such objections by revising Permitted and Ought through adding a further condition to the antecedent: for example, that the agent is in principle able to form or ground the belief in question in an adequate way. One can also avoid such objections by thinking of Permitted and Ought as ceteris paribus principles. I am sympathetic to both strategies of avoidance. Mutatis mutandis, my argument would also apply to such revised versions of Permitted and Ought. Furthermore, some epistemologists might argue against Permitted and Ought as follows: for being permitted or even required to believe the proposition that is stably supported by the total evidence, one needs to be aware of the evidential support the total evidence lends to the proposition. Evidential support without such awareness is not sufficient for being permitted or even required to believe. However, one could avoid such an objection by adding as a further condition to the antecedent of Permitted and Ought that the agent is aware of the evidential support. I do not think that such awareness is required. Young children are hardly aware of the evidential support even in cases where it is certainly rational for them to believe a given proposition. In any case, most—if not all —of what I argue for is independent of whether one adds this further condition to the antecedent. For simplicity, I stick to Permitted and Ought.

${ }^{5}$ For a discussion of indirect epistemic teleological positions, see for example Berker (2013) . 
Epistemic Teleology If it is epistemically rational for an agent $s$ to believe a proposition $p$ given $s$ 's total evidence $e_{s}$, then $s$ 's believing $p$ adequately serves (or would serve) the appropriate epistemic end given $e_{s}$.

To start with let's be neutral and assume that the appropriate end is adequately served when it is actually served or when it is probably served given the agent's total evidence. My first criticism of specifications of Epistemic Teleology holds in both cases and is neutral in this respect. Later, however, in Sects. 2.4 and 2.5 I will no longer be able to remain neutral, and will specify when the serving relation is adequate.

Here, Epistemic Teleology is not understood as a characterization of epistemic rationality. Epistemic rationality is characterised by Evidentiali sm $^{S}$. Epistemic Teleology is understood as a position that promises to be able to explain the epistemic normativity of rationality. This leads us to the following question:

Main Question Does Epistemic Teleology support Permitted or even Ought; and, if so, which?

\subsection{Aim and plan}

In this article, my primary aim is to answer the Main Question from an epistemic perspective that adopts Evidentialism ${ }^{S}$ and Epistemic Teleology. (In this article I do not challenge Epistemic Teleology and Evidentialism ${ }^{S}$. I think they are plausible enough to be the basis of further investigation.) I answer the Main Question by claiming that Epistemic Teleology supports Permitted but not Ought. To argue for my answer I proceed as follows: first, in Sect. 2, I discuss and criticise specifications of Epistemic Teleology that refer to two popular epistemic ends that are discussed in the literature. These ends are: the end of having a large set of beliefs with the best possible ratio between true and false beliefs (the ratio end), and the end of believing a proposition if and only if it is true (the end of inquiry). I argue that if the appropriate epistemic end referred to by Epistemic Teleology is one of these ends, the normativity of epistemic rationality can only be established as being conditional, stipulated, or semi-epistemic. While I do think that such kinds of normativity can play an important role in epistemology, I go a step further and explore whether there is a less restricted account of the normativity. In Sect. 3, I present and endorse my radical specification of Epistemic Teleology. This specification allows for such a less restricted account. According to my specification, the appropriate epistemic end referred to by Epistemic Teleology is the end of believing a proposition only if it is true (the end of avoiding falsity). In the subsequent section, Sect. 4, I provide an answer to the Main Question by arguing that my specification of Epistemic Teleology (together with a plausible principle) supports Permitted but not Ought. It is thereby crucial that my position, and my answer to the Main Question, does not exclude that some further principles-for example, principles that are not teleological in spirit—might be added and so provide support for Ought. I conclude Sect. 4 by dispelling some worries that have been raised about my position. Concluding, I review my results in Sect. 5.

(Since I am primarily concerned with epistemic rationality and epistemic normativity, in the following, I often skip the reference to the epistemic dimension.) 


\section{The ratio end and the end of inquiry}

\subsection{The ratio end}

Epistemic Teleology claims that if it is rational for an agent $s$ to believe a proposition $p$ given $s$ 's total evidence $e_{s}$, then $s$ 's believing $p$ adequately serves the appropriate epistemic end given $e_{s}$. It is often assumed that the appropriate epistemic end in question is valuable and one is committed to pursuing it. The normativity of rationality is then based on the value of this end. The question thus arises: What is the appropriate epistemic end? There is no room here to discuss all candidate ends. However, before I present my preferred end, I focus on two popular ends that come readily to mind: first, the ratio end, which is the global epistemic end of having a large set of beliefs with the best possible ratio between true and false beliefs, and, second, the end of inquiry, which is the local epistemic end of believing a proposition if and only if it is true. ${ }^{6}$ I begin by introducing and quickly dismissing the specification of Epistemic Teleology that refers to the ratio end. I then focus in more detail on a specification that refers instead to the end of inquiry. Eventually, I will also dismiss this specification and replace it with my own.

Let's start with the following end:

Ratio End The ratio end is the global epistemic end of having a large set of beliefs with the best possible ratio between true and false beliefs.

\subsection{A first specification of Epistemic Teleology}

Specifying Epistemic Teleology in terms of the ratio end gives us:

Epistemic Teleology ${ }^{R E}$ If it is rational for an agent $s$ to believe a proposition $p$ given $s$ 's total evidence $e_{s}$, then $s$ 's believing $p$ adequately serves the appropriate ratio end given $e_{s}$.

It is easy to present counterexamples to Epistemic T eleology $R E$ where the proposition in question is stably supported by the total evidence and, given Evidentialism ${ }^{S}$, it is rational to believe the proposition in question, but believing the propositions does not serve or does not probably serve the ratio end given the total evidence. Such examples show that the antecedent of Epistemic Teleology ${ }^{R E}$ can be satisfied even if its consequent is not satisfied. Think of cases where by believing a proposition that is stably supported by your total evidence you are led to believe a lot of false beliefs such that you end up having a large set of beliefs with a ratio between true and false beliefs that is worse than the ratio before you believed the proposition. The following example is such an example:

\footnotetext{
${ }^{6}$ For literature that shows that the ratio end or variants of it are accepted by many epistemologists, see Douven (2008, sect. 2). For a discussion of a number of truth-related epistemic goals see David (2014). My distinction between local and global epistemic ends traces back to Kelly (2003). Kelly distinguished between local and global "cognitive aims", where the former concerns specific propositions. Similarly, David (2014, sect. II) distinguishes between "individual relativized [true-belief] goals, one for each proposition" and "collective true-belief goals".
} 
Demon Example Demon wants Christine to believe that he is caring. Christine has grown up with him and has acquired a body of total evidence that (stably) supports that he is not caring. Demon threatens Christine that if she believes that he is not caring, he will make a lot of her current beliefs false. Christine is aware that he has the power to do this and that he is honest despite being not caring.

Examples such as this show that specifications of Epistemic Teleology that are couched in terms of the global ratio end and initially seem plausible have trade-off problems and, thus, are not that plausible after all. ${ }^{7}$ Let's see whether specifications in terms of the local end of inquiry do better. ${ }^{8}$

\subsection{The end of inquiry}

The local end of inquiry (with respect to a proposition) consists of two components: first, the local end of including truth, which is the end of believing a proposition if it is true; and, second, the local end of avoiding falsity, which is the end of believing the proposition only if it is true. This amounts to the following characterisation of the end of inquiry:

End of Inquiry The end of inquiry with respect to a proposition is the local epistemic end of believing the proposition if and only if it is true. ${ }^{9}$

Before we focus on a specification of Epistemic Teleology in terms of the local end of inquiry, note that although I often speak-for the sake of simplicity —as if there were only one such end, strictly speaking there are as many ends of inquiry as propositions. Each of the ends corresponds to a specific proposition.

\subsection{A second specification of Epistemic Teleology}

A specification of Epistemic Teleology in terms of the end of inquiry results in the following:

Epistemic Teleology ${ }^{E I}$ If it is rational for an agent $s$ to believe a proposition $p$ given $s$ 's total evidence $e_{s}$, then $s$ 's believing $p$ adequately serves the appropriate end of inquiry with respect to $p$ given $e_{s}$.

A moment's reflection reveals that-in contrast to Epistemic Teleology ${ }^{R E}$ — this specification does not suffer from trade-off problems because the epistemic end is relativised to the proposition in question.

\footnotetext{
7 Demon Example is a modification of Christensen's (2004, ch.1) three-fingered alien example. Similar examples that concern trade-off problems are also discussed in Ahlstrom-Vij and Dunn (2014), Berker (2013, 2015), David (2014), Firth (1981), Fumerton (2001) and Goldman (2015). The examples there, however, are presented as counterexamples to other teleological positions. In the prequel of this article, I discuss the crucial differences between these teleological positions and counterexamples, and Epistemic Teleology and my counterexamples.

8 See, similarly, Fumerton (2001).

9 See also David (2014) for a discussion of such local ends.
} 
Without further qualification, however, Epistemic Teleology ${ }^{E I}$ has another problem. I have been neutral with respect to whether the ratio end is adequately served just in case it is actually served or just in case it is probably served. However, if we remain neutral, we still run into problems. The former understanding of the serving-the-end relation is to be rejected. If Epistemic Teleology ${ }^{E I}$ is to be taken seriously, the end is certainly not adequately served just in case it is actually served. This becomes clear as soon as one considers cases where the proposition in question is false but stably supported by the total evidence. ${ }^{10}$ Given Evidentialism ${ }^{S}$ it is, then, rational to believe the proposition although the end of inquiry with respect to the proposition is not actually served (given the total evidence) because the proposition is false. Believing a false proposition certainly does not actually serve the end of believing this proposition just in case it is true. If Epistemic Teleology ${ }^{E I}$ is further specified in terms of actuallyserving-the-end, such cases with respect to false propositions show that the antecedent of Epistemic Teleology ${ }^{E I}$ can be satisfied without the consequent being satisfied. ${ }^{11}$

\subsection{A third specification of Epistemic Teleology}

If one specifies Epistemic Teleology $y^{E I}$ in terms of evidential probabilities in the following way, one avoids the problem of Epistemic Teleology ${ }^{E I}$ just mentioned:

Epistemic Teleology $y_{P}^{E I}$ If it is rational for an agent $s$ to believe a proposition $p$ given $s$ 's total evidence $e_{s}$, then $s$ 's believing $p$ probably serves the appropriate end of inquiry with respect to $p$ given $e_{s}{ }^{12}$

EpistemicT eleology ${ }^{E I}$ runs into problems when a false proposition is stably supported by the total evidence and the local end of inquiry with respect to the proposition is adequately served (given the total evidence) just in case it is actually served (given the total evidence). This is so because the end is never actually served when the proposition is false. This is independent of whether it is rational to believe the proposition. One might think that Epistemic Teleolog $y_{P}^{E I}$ has a similar problem-one might think, perhaps, that the probability referred to in Epistemic Teleolog $y_{P}^{E I}$ is low as soon as the proposition in question is false, and that this results in a similar problem as before. However, the problem does not arise if one understands the probability referred to in Epistemic Teleology $y_{P}^{E I}$ as evidential probability. And this is exactly how the probability in question is understood here-as evidential probability (see also Eder 2019). The evidential probability of a proposition given the total evidence reflects how strongly the evidence supports the proposition. It can be understood as Brössel's (2012) and Brössel and Eder's (2014) reasoning commitments, which trace back to Levi's (1974, 1980) confirmational commitments, Maher's (2006) inductive probabilities, or Williamson's (2000) objective evidential probabilities. ${ }^{13}$ If one understands

\footnotetext{
10 Such cases are obviously impossible if evidence is factive and evidential support is exclusively deductive. However, I certainly do not want to assume that evidential support is always deductive.

11 See also Maitzen (1995).

12 As understood here, something is probable just in case the probability of it is equal to or above the appropriate threshold $t$, where $t$ is above .5 .

13 Since the epistemic status of evidential probabilities does not depend on particular worlds, Epistemic Teleology ${ }_{P}^{E I}$ doesn't fall prey to a new evil-demon-style example. This is also true for the
} 
the relevant probability as evidential probability in this way, the evidential probability of a target proposition is not low as soon as the proposition is false. Unless the total evidence correctly specifies the truth-value of the proposition, the truth-value of the proposition usually does not have an influence on the evidential probability. (It is different — of course — when the truth-value of the proposition is logically determined. In such a case, the evidential probability is also logically determined.)

In many respects, I am sympathetic to Epistemic Teleology $y_{P}^{E I}$ as a specification of Epistemic Teleology. Indeed, in the prequel of this article, I defend Epistemic Teleology $y_{P}^{E I}$ against objections that have been presented against it. In the following, I take a closer look at the normativity that comes with this specification. I argue that if the appropriate epistemic end referred to by Epistemic Teleology is the end of inquiry, the normativity of epistemic rationality is merely conditional, stipulated, or semi-epistemic. To be more precise, I argue that with Epistemic Teleology $y_{P}^{E I}$ we can only establish the normativity as being conditional, stipulated, or semi-epistemic. There is nothing wrong with the normativity being conditional or semi-epistemic. However, if in addition we hope to establish the normativity of rationality as also being less restricted, as some epistemologists do, ${ }^{14}$ we should go a step further and look for another specification of Epistemic Teleology. This is what I do in the next section, but first let's take a closer look at the normativity associated with Epistemic Teleology $y_{P}^{E I}$.

With the help of specifications of Epistemic Teleology such as Epistemic Teleolog $y_{P}^{E I}$, we want to explain the epistemic normativity of rationality. And we want to explain it by arguing that believing propositions that are rational for one to believe probably serves the appropriate epistemic end, which is valuable and one is committed to pursuing. The epistemic normativity of rationality then traces back to the valuable epistemic end. The end might be valuable because it is the aim of an agent, since it is valuable for the agent; or the end might be valuable in general and independent of single agents.

In the following, I focus on the value of our particular end under consideration here, the local end of inquiry (with respect to a proposition). First, let's consider the case where the end of inquiry is the aim of an agent and as such is valuable for the agent. After that, I focus on the possibility that the end of inquiry is valuable in general and independent of single agents.

If the end of inquiry is the aim of an agent, one can explain the value of it in a simple, straightforward way, and based on this one can explain the normativity of rationality. The aim seems to be valuable for the agent and the agent is committed to pursuing it. ${ }^{15}$ However, if the end of inquiry is not an aim of an agent, then the normativity of rationality - which is what we are trying to explain-is only conditional, namely conditional on the end being pursued as an aim by the agent. As an analogy, consider financial rationality and the corresponding end of increasing one's riches. If one does not pursue this end, then an action can be financially rational without it

specification of Epistemic Teleology that I discuss next. I am grateful to a referee of the previous version of this article for prompting me to make this clear.

14 See, for instance, Kelly (2003).

15 See, similarly, Brössel et al. (2013). 
being of any value for one. Financial rationality for one does not have any normative force, and would be only conditionally valuable and normative: if one adopted the end of increasing one's riches, then it would become unconditionally valuable and normative. ${ }^{16}$ The same seems true here. Epistemic Teleolog $y_{P}^{E I}$ does not necessarily have the advantage that it helps to explain the normativity of rationality, since the agent might not be committed to pursuing the end of inquiry, which might not even be valuable in general. If Epistemic Teleolog $y_{P}^{E I}$ refers to an epistemic end that is only conditionally valuable, that is, valuable conditional on being pursued as an aim, the normativity of rationality, or rationally believing, is also only conditional on that.

In the hope of establishing a less restricted account of epistemic normativity, I proceed to examine whether one can show that the end of inquiry is valuable in general and independent of single agents. The hope is that the normativity of rationality is not merely conditional on the end of inquiry being pursued as an aim, and that the end is an appropriate, valuable end that one is committed to pursuing.

Recall that the local end of inquiry (with respect to a proposition) consists of two components: first, the end of believing a proposition if it is true (i.e., the end of including truth); second, the end of believing the proposition only if it is true (i.e., the end of avoiding falsity). For the time being let us adopt the second component unchallenged, on the proviso that we shift our focus to it in due course (in Sect. 3). I can think of four accounts that are promising for establishing the end of including truth as an end that one is committed to pursuing and that is valuable in general-valuable, that is, independently of whether one actually pursues it as an aim. In the following, I present and discuss the accounts. In my criticism of the first two accounts, I lean heavily on Grimm's (2009) instructive discussion of them. The fourth account is the one that he himself suggests.

Regarding the first account, the end of including truth is intrinsically valuable. As Grimm (2009) notes, many epistemologists think that it is intrinsically valuable to believe true propositions. They often argue for this on the basis that we value believing true propositions not only because of their practical usefulness, but because as curious human beings we are simply interested in the truth. However, this is certainly not true for all propositions. Grimm rightly points out that there are so-called trivial truths that we usually do not value. Consider for example trivial truths such as whether or not the number of grains of sand on Lomas de Arena is even. ${ }^{17}$ For such propositions, it does not seem that we are committed to pursuing the end of including truth. We do not value believing propositions just because they are true. It is therefore unconvincing to refer to our curiosity in order to argue that believing true propositions is intrinsically valuable. Admittedly, that we do not value all true beliefs does not entail that they are not valuable simply because they are true. However, we are still lacking an argument in support of the claim that believing true propositions is intrinsically valuable. I am not aware of any good argument that establishes that for any true proposition-including trivial truths - to believe it is intrinsically valuable. However, without such an argument there is no reason to assume that believing true propositions is intrinsically valuable

\footnotetext{
16 See, similarly, Brössel et al. (2013).

17 This example is my variation of stock examples for trivial truths. Lomas de Arena are sand dunes in Santa Cruz, Bolivia.
} 
and, thus, that we are committed to pursuing the end of including truth. My point here is not that the end of including truth cannot be intrinsically valuable; it is rather that it is not clear how we can establish that it is. I think the following description of a scenario presented by one of the referees of the previous version of this article comes close to establishing the intrinsic value of believing true propositions:

[C]ompare two beliefs in trivial truths; stipulate that nothing practical hangs on either, but one is false and one is true. Which belief would it be better to hold? Which belief is better from an epistemic point of view? If truth is of no intrinsic value, it should make no difference in value to which belief the subject held. But it seems that of the two beliefs, the true one is more valuable. We value the true over the false; we value the authentic over the fake, even when nothing else hangs on it.

One is certainly often tempted to value true beliefs more than false beliefs in a setting such as that described here. However, I am not sure this is always the case. Sometimes one might be indifferent among the beliefs, for instance when the true proposition is a trivial truth. But even if it were true that we always value true beliefs more than false beliefs in scenarios just as that described above, I do not see how one could establish that what is valued is intrinsically good (or bad) merely by appealing to what we de facto value (or disvalue). Furthermore, arguing that the value of true belief is higher than the value of false belief does not suffice to establish the intrinsic value of true beliefs. If true beliefs are intrinsically valuable, then holding them is better than not holding them. It is not clear how one can establish this in support of the account in question. If, however, appeal to our value judgements is a legitimate tool for establishing the intrinsic value of believing true propositions, as the referee seems to suggest, then we would always value true beliefs over no belief. However, as discussed above, this does not seem to be the case with respect to trivial truth. We still lack an argument that establishes that the end of including truth is intrinsically valuable.

In the absence of an argument that establishes the intrinsic value of the end, we are left with the option of merely stating or assuming the value. And merely stating or assuming it is tantamount - or at least comes close - to stipulating it. We might as well have stipulated that rationality, or rationally believing, is normative without trying to explain it with the help of Epistemic Teleology. Some epistemologists think that believing true propositions and achieving the end of inquiry is intrinsically valuable and that there is no need to explain this. This is not satisfactory if one is in search of something more elucidating. Let's see whether we can do better.

According to the second account, which traces back to Sosa (2007), the end of including truth is valuable within the epistemic domain, even if it is not necessarily valuable outside that domain - just as the end of monetary gain is valuable in the financial domain. This would be to assign such ends a value which is independent of whether monetary gain is valuable outside the respective domain. Sosa even defends the view that truth in general is the fundamental value within the epistemic domain, "the ultimate explainer of other distinctively epistemic values" (2007, p. 72). Many epistemologists assume that it is constitutive of epistemology that the end of including 
truth is valuable; indeed they often do so not only without argument, but without an argument to establish that one does not need an argument. Even if there were a good argument in favor of this account, the normativity associated with it would be restricted to the epistemic domain, since truth would only be valuable within the epistemic domain. I agree with Grimm (2009), who criticizes Sosa's account for not being able to explain the special status of epistemic evaluations outside the domain, since it does not account for the binding force of epistemic evaluations which they exert independently of the domain, or outside the domain. At best, it provides a label for a domain in which we value believing true propositions - that is, the epistemological domain. It does not provide a reason to engage in the epistemological domain or to adopt the end of including truth in the first place. Grimm remarks that "even though we can evaluate beliefs relative to countless different domains, the end of realizing the truth enjoys a special sort of status when it comes to the evaluation of belief" (2009, p. 256).

One can admit that the normativity is restricted to the domain and think that this is fine since we are always epistemic beings and our beliefs can always be judged within this domain. There is nothing wrong with that. However, the normativity would still be restricted to the domain even in the case that we always judge it as within the domain. To offer an analogy, we are always biological beings and we can always judge ourselves or what we do within the domain of biology; however, this does not establish any kind of normativity outside the domain.

I hope to establish the normativity of rationality as also being less restricted. So let's try to go a step further and look for an account that allows for this. One could indeed simply stipulate - without explanation — that the end of including truth has a binding force that makes epistemic evaluations based on it somehow special outside the domain; however, let us_-again—seek a more illuminating approach.

The third account claims that the end of including truth is of value for agents because true beliefs help agents to act successfully by achieving their practical aims; it is of practical use to believe true propositions. This account is commonly attributed to Kornblith (1993). Without going into much detail, let me distinguish two variants of the present account: according to the first, the end of including truth is of value because each true belief helps an agent to act successfully by achieving the agent's particular aims. In contrast, according to the second variant, the end of including truth is of value because true beliefs in general help agents to act successfully in general, even if it is not the case that each particular true belief helps in this way. ${ }^{18}$ Let me begin by focusing on the first variant of the present account, and then turn to the second.

Initially, it seems promising to assume that the end of including truth is valuable because each true belief helps an agent to act successfully by achieving the agent's particular aims. No doubt there are situations where achieving the end of including truth with respect to a proposition is valuable because believing the truth about this particular proposition helps one to act successfully with respect to a particular aimhardly anyone disagrees here. For instance, it may be valuable for an agent to form a true belief about whether or not stock prices will rise tomorrow because having a true belief about this can help the agent to reach the practical aim of increasing riches.

$\overline{18}$ This variant is certainly more in the spirit of Kornblith. 
However, in line with Kelly (2003) and Papineau (2013), there are many propositions for which there is no such relevance for our actions and practical aims. It may be true, for example, that the number of grains of sand on Lomas de Arena is even and that the true belief in this proposition is for all intents and purposes irrelevant to anyone's practical aims. We sometimes lack the relevant practical aim; even worse, as Papineau (2013) notes, believing the truth about a proposition might sometimes stand in conflict with one's practical aims. Consider the following example, which is my slight modification of Nozick's (1993) famous grieving mother example:

Grieving Mother Example A grieving mother whose beloved son has recently died receives pieces of evidence such that her total evidence stably supports that her son was a brutal criminal who caused much suffering. It is rational for her to believe that her son was a brutal criminal who caused much suffering. However, believing this about her son does not increase her happiness, and rather causes her more suffering. She definitely does not want to commemorate her son in this way, but rather as a decent human being-whatever this might be.

Her believing the truth about her son's guilt does not serve the mother's practical aims of commemorating her son as a decent human being. Two possible replies come to mind.

First, one could reply that believing the truth about his guilt is not immediately relevant with respect to the mother's commemoration of her son as a decent human being, but it might turn out to be relevant later in her life with respect to other practical aims. While such a reply seems tenable concerning the grieving mother, an analogous reply concerning the grains of sand on Lomas de Arena does not seem tenable. ${ }^{19}$

Second, one could reply that even if a particular true belief with respect to a particular proposition might never turn out to be relevant for an aim any agent might have, the end of including truth with respect to the proposition might have some default value. While I am sympathetic to this appeal to a default value, ${ }^{20}$ defendants of it have to cope with the challenge that sometimes one might simply know about a particular proposition that believing it is and never will be relevant to anyone. ${ }^{21}$ There is much

19 Papineau makes in essence the same point and presents an example that is similar to the example here. His example shows that holding false beliefs can be of value:

"Sometimes there will also be a positive value to having false beliefs. Suppose some quite untreatable form of cancer is common in John's family and that he indeed has it. There is a simple enough test, but John doesn't take it, because he is confident that he doesn't have the cancer. (He feels great!) As a result, he avoids the distress and unhappiness that would be occasioned by his learning the truth. Now, John hasn't bothered to check his belief, and as a result has persisted in a falsity. But, supposing this makes no practical difference to anybody (the cancer is untreatable, remember), I say that he has done nothing wrong at all. I recognize no doxastic offence that weighs against the advantage of his avoiding the truth" (Papineau 2013, p. 68).

20 For a similar account that regards the end of inquiry-or a variant of it-as a default goal, see Brössel et al. (2013).

21 See also Papineau (2013). 
more to say about the appeal to a default value, but since it plays—at best—hardly any role for what I argue for in the end, I will not explore this any further here.

Let's move to the second variant of the account. According to this variant, the end of including truth is of value because true beliefs in general help agents to act successfully in general. It is thereby not required that each belief in a particular proposition helps us to act successfully in order for the end of including truth to be valuable. The end of including truth gets its value in virtue of true beliefs being of a valuable type. ${ }^{22}$ Very roughly, the end of including truth is valuable because many or most true propositions are of practical use, which makes true propositions of a valuable type. There is no requirement that all true beliefs be of such use.

This variant and the former variant of the present account have in common that they can only explain a semi-epistemic value of the end of including truth. I refer to it as semi-epistemic because the end of including truth is an epistemic end which is valuable due to non-epistemic factors. Unfortunately, I am not in a position to draw a sharp line between the epistemic and non-epistemic dimensions. Recent literature suggests that this is difficult. ${ }^{23}$ However, it should be clear that, given the present account and Epistemic Teleology $y_{P}^{E I}$, the normativity of rationality is also influenced not only by epistemic but also by non-epistemic factors, which makes them semi-epistemic as well.

I consider this third account to be more attractive than the first two accounts. Recall that according to the first, the end of including truth is intrinsically valuable; and according to the second, it is valuable within the epistemic domain. The first two accounts are-or come close to being-tantamount to stipulating the value of the end of including truth and are hardly illuminating: therefore, they are not helpful in explaining the normativity of rationality.

Now let's consider an alternative account, the fourth account, which traces back to Grimm. According to it, we should change our perspective "away from the standard first-person question about the value of true belief-wherein we ask (as Goldman, Alston, and Lynch asked) about the value of true belief in terms of our own intellectual aims or well-being — and by moving instead towards a more communal or social view of the value of truth" (Grimm 2009, pp. 257-258). Thus, the relevant end should be one that is valuable for society, even if it is not valuable to all members of society with respect to all propositions at all times. Grimm claims that "given our nature as information-dependent and information-sharing creatures, we have an obligation not just to be sources of information for others but to be good sources of information" (Grimm 2009, p. 259). While Grimm focuses on believing the truth in general, what he says can easily be applied to the end of inquiry or-to be more precise - to its first component. Accordingly, we can consider the end of inquiry to be a common good that is of value for society because it fosters the well-being of society. The present account is certainly attractive. For instance, it helps to explain the value and normativity associated with believing the truth about human-induced climate change. Even if this true belief were not of any value concerning one's personal practical aims, to believe

\footnotetext{
22 See Goldman and Olsson (2009) for a similar turn when they explain the value of beliefs that are formed by reliable processes.

23 See Cohen (2016).
} 
the truth about climate change is certainly of high value for society. However, there still might be true beliefs that are irrelevant for the well-being of society. ${ }^{24}$ As mentioned before, the truth about whether or not the number of grains of sand on Lomas de Arena is even seems to be a good candidate for such a proposition. I can think of two possible replies, and they are analogous to the replies we saw earlier concerning the third account and the Grieving Mother Example.

First, one could claim with Grimm (2009, sect. 6) that even if a particular proposition initially seems to be irrelevant for the well-being of society, achieving the end of including truth with respect to it might turn out to be relevant for society as a whole or for some members of it, and, therefore, for society. If one think that sometimes one simply knows that believing a particular proposition is not relevant at all, this reply is not convincing. This is similar to what I said before concerning the third account. However, while it was plausible that one can know that the truth of a proposition won't play a role for a specific agent, it is not clear that one can know that it won't play a role for any agent at any time. ${ }^{25}$ Anyhow, the end might still have a default value for the well-being of society. We are left with a debate similar to before.

Second, one could claim, also similar to before, that the end of including truth is valuable because it is of a valuable type. This is so because true beliefs are in general valuable for the well-being of society, even if a particular end of including truth or a particular true belief is not.

Either way, the resulting value of the end of including truth turns out to depend on non-epistemic factors about society's well-being — as Grimm himself emphazises. The value is once again semi-epistemic: it traces back to an end that is epistemic but valuable due to non-epistemic factors. Although both variants of this fourth account are attractive, I now proceed to see whether we can present another account that allows the value of the end of including truth not to be influenced by non-epistemic factors.

Up till now, it seems, one is left with accounts according to which we can only establish the value of the end of including truth as being merely conditional, stipulated, or semi-epistemic. Without further specifications - and perhaps further principlesEpistemic Teleology $y_{P}^{E I}$ can only explain the normativity of rationality as merely conditional, stipulated, or semi-epistemic. Let's see whether there is an alternative specification of Epistemic Teleology, according to which the normativity is less restricted. In exploring a less restricted version, I do not mean to indicate that there is something wrong when the normativity is merely conditional, stipulated, or semiepistemic. However, as mentioned before, it is common for epistemologists to believe in or look for an epistemic normativity that is less restricted. For this reason, instead of stopping here I go a step further, and explore another specification of Epistemic Teleology according to which the normativity associated with it is less restricted.

\footnotetext{
24 See, similarly, Papineau (2013, sects. 4, 10).

25 See (2009, sect. 6.).
} 


\section{The end of avoiding falsity}

\subsection{The end of avoiding falsity}

The end of inquiry with respect to a proposition consists of two components: first, the end of including truth; second, the end of avoiding falsity. So far we have not managed to establish the first component as an appropriate end to which we are committed and whose value is not merely conditionally, stipulated, or semi-epistemic. What, then, of the second component, which I refer to as the end of avoiding falsity (with respect to a proposition)?

End of Avoiding Falsity The end of avoiding falsity with respect to a proposition is the local epistemic end of believing the proposition only if it is true.

Why should we adopt this end as the appropriate end referred to in Epistemic Teleology? It seems natural to evaluate a belief by considering whether it satisfies a primary end of believing. A primary end-if not the primary end-of having a belief is that the belief represents the world correctly, that is, that the believed proposition is true. I think that to believe a proposition is to take this proposition to be true. The value of believing a proposition then depends on whether or not the proposition is true. This idea about the end of beliefs accounts for the value of the end of avoiding falsity itself, as shall become clear in the following paragraphs. ${ }^{26}$

My position has some similarities with Wedgwood's (2002). He endorses the following, which he takes to be the fundamental epistemic norm: roughly put "a belief is correct if and only if the proposition believed is true" (2002, p. 268, and pp. 272-273, 289). According to Wedgwood, the term "correct' "expresses a normative concept". Related to this concept he "propose[s] that certain concepts are normative because it is a constitutive feature of these concepts that they play a regulative role in certain practices" (2002, p. 268). He "argue[s] that the concept of 'rational belief' is normative for the practice of theoretical reasoning" (2002, p. 271). Whereas I am neutral with respect to constitutive features of the concept of rational belief and constitutive features of belief, Wedgwood (2002, sect. 2) focuses on such constitutive features. But I agree with him that a belief is to be evaluated with respect to whether it is true. From this, however, one cannot establish that to believe a true proposition is always valuable. Similar to him, I think that whether one engages in a practice of believing is relevant for whether true belief is valuable. It is not valuable per se. Even if a belief is correct just in case it is true, this does not imply that true beliefs are valuable per se, rather they are valuable given that one engages in the practice of believing. However,

\footnotetext{
26 To some extent, the relation between belief and the end of avoiding falsity might be even stronger. I am sympathetic - but not committed - to a view according to which we would call a propositional attitude 'a belief' only if the agent thereby is committed to pursuing the end of avoiding falsity with respect to that attitude; a propositional attitude without such a commitment might be a hope, a wish, or something similar, but it is not a belief. (See Papineau (2013) for criticism of variants of such a view. Papineau also discusses the function of beliefs and criticises an account that is in the vicinity of my account here with respect to the end of beliefs. There is no room here to compare his account with mine.)
} 
false beliefs are to be avoided. We are only committed to pursuing the appropriate end of avoiding falsity: to believe a proposition only if it is true. ${ }^{27}$

I think something is wrong when one engages in a practice-such as believingthat is not bad, and yet the practice's end is not fulfilled. To fulfil the end seems in one way or another to be good. From an epistemic point of view there is nothing wrong in engaging in the practice of believing, and it is the epistemic dimension we are interested in here. If you engage in the practice of believing, then your belief better be true! The end of avoiding falsity is valuable and we are committed to pursuing it. However, there is no commitment and nothing particularly good or bad about engaging in the practice of believing in the first place. We are not required to form beliefs just because they are true or because they are probably true given our total evidence. ${ }^{28}$ Similarly, Wedgwood says: "Admittedly, if $p$ is an utterly tedious or trivial truth, then it may be a complete waste of time even to consider $p$. But the fundamental epistemic norm says nothing about whether or not one should consider $p$, since this norm only concerns propositions that one actually consciously considers" (2002, p. 273). ${ }^{29} \mathrm{We}$ are not committed to pursuing the end of including truth (i.e., the first component of the end of inquiry), but we are committed to pursuing the appropriate end of avoiding falsity.

Note that the appropriate end of avoiding falsity with respect to a proposition can easily be served by not forming any doxastic attitude toward the proposition in question. This has important implications for our answer to the Main Question, as we observe in the following.

\subsection{A radical specification of Epistemic Teleology}

In the light of what was said above, I propose a specification of Epistemic Teleology which is-I think - the best we can do on behalf of advocates of Epistemic Teleology who want to explain the normativity of rationality, or rationally believing, and try to establish it as being not merely conditional, stipulated, or semi-epistemic:

\footnotetext{
27 This is in a similar spirit to what Wedgwood conveys with the following analogy: "For example, engaging in the 'ordinary practice of playing chess' presumably involves aiming to win a game of chess by making only legal moves" (2002, p. 268). I think this is close to the truth. The practice commits one to aiming to win the game but it does not involve aiming at winning. Sometimes one plays chess without aiming to win. Parents can play chess with their children without aiming at winning. But if they did it correctly, they would aim at winning and they are committed, or required, to aim at winning. However, similar to believing, there is no commitment to engage in the practice of playing chess.

${ }^{28}$ Steglich-Petersen (2011) makes a related point but on different grounds. There is no room here to compare his approach with mine, since his is couched in a different framework and mainly in terms of reasons.

29 Wedgwood's position and my position share some similarities, some of which I indicate above. To compare the positions in further detail must be left to another occasion, especially since the focus in his case is different. His focus is more on what is constitutive for belief, fundamental epistemic norms, practical considerations, reliabilist positions, and whether and when something counts as rational belief in the first place-all topics that don't play such a primary role in my account. Wedgwood does not present his account in terms of the value of truth but rather as whether a belief is correct just in case it is true. He evaluates a belief in the context of considering the proposition in question. Wedgwood is interested in finding the most fundamental norm of all norms, while my focus is more narrow. I am concerned with whether the correct specification of Epistemic Teleology speaks in favour of Permitted or Ought.
} 
Epistemic Teleology $y_{P}^{E A F}$ If it is rational for an agent $s$ to believe a proposition $p$ given $s$ 's total evidence $e_{s}$, then $s$ 's believing $p$ probably serves the appropriate end of avoiding falsity with respect to $p$ given $e_{s}$.

(The probability is again understood as evidential probability.)

Once we assume Epistemic Teleolog $y_{P}^{E A F}$, the normativity of rationality is no longer merely conditional, stipulated, or semi-epistemic. The epistemic normativity of rationality traces back to the value of the end of avoiding falsity, which is not merely conditional, stipulated, or semi-epistemic.

With Epistemic Teleolog $y_{P}^{E A F}$ framed in terms of the end of avoiding falsity, we can now turn to the Main Question. In the following section, I look for answers to the specification of the question that refers to Epistemic Teleolog $y_{P}^{E A F}$ : Does Epistemic Teleology $y_{P}^{E A F}$ support Permitted or even Ought; and, if so, which?

\section{Permitted but not Ought}

\subsection{In favor of Permitted}

According to Epistemic Teleolog $y_{P}^{E A F}$, if it is rational for an agent $s$ to believe a proposition $p$ given $s$ 's total evidence $e_{s}$, then $s$ 's believing $p$ probably serves the appropriate end of avoiding falsity with respect to $p$ given $e_{s}$. The epistemic normativity of rationally believing $p$, or rationality, then, traces back to this appropriate epistemic end-which is a valuable end - that we are committed to pursuing. What serves or probably serves something valuable that we are committed to pursuing is permitted. This comes down to the following:

Avoiding Falsity and Permission If an agent $s$ 's believing a proposition $p$ probably serves the appropriate end of avoiding falsity with respect to $p$ given $s$ 's total evidence $e_{s}$, then $s$ is (epistemically) permitted to believe $p$ given $e_{s}$.

Before I move on, let me note two things.

First, note that it is not required that the probability is the highest possible of all alternatives. It suffices that it is probable (i.e., equal to or above the appropriate threshold $t$, where $t$ is above .5). I think that it is safe to say that we are often permitted to do all sorts of things even if for some alternatives it is more probable that they lead to the end in question. We are often permitted to do things because it is highly probable that they lead to relevant ends. I think various alternatives can be permitted at the same time even though the probabilities of them leading to the appropriate end in question are not equally high. As long as the probability is high enough this suffices for permission. Compare this to a case of practical permission. Consider the following case: You are contractually committed to the end of arriving for work at 9 a.m. Nevertheless, you are permitted to arrive there by car even though there is a higher probability of arriving at work in time via public transportation. It suffices that the probability of arriving at work on time given that you take your car is high enough. Similarly, you are epistemically committed to the doxastic end of not believing false 
propositions. You are permitted to believe what it is rational to believe even though there is a higher probability of satisfying the doxastic end if you choose the alternative, i.e., not holding any doxastic attitude towards the proposition in question.

Second, note that there might also be cases where to do what is permitted according to Avoiding Falsity and Permission leads to some conflicts. However, by endorsing Avoiding Falsity and Permission one is not committed to the view that the permission in question is strict and holds under every circumstance. As mentioned before, the permission may be mere pro tanto permission, may be defeated or trumped by other permissions or obligations, or it might even be in conflict with other permissions or obligations. That said, we can now turn to the answer to our Main Question.

Avoiding Falsity and Permission together with Epistemic Teleology $y_{P}^{E I}$ imply:

Permitted If it is epistemically rational for an agent $s$ to believe a proposition $p$ given $s$ 's total evidence $e_{s}$, then $s$ is (epistemically) permitted to believe $p$ given $e_{s}$.

Epistemic Teleology $y_{P}^{E A F}$ (together with a plausible principle) supports Permitted. The question arises whether Ought holds as well. Recall, Ought claims the following:

Ought If it is epistemically rational for an agent $s$ to believe a proposition $p$ given $s$ 's total evidence $e_{s}$, then $s$ (epistemically) ought to believe $p$ given $e_{s}$.

In order for the consequent to hold, believing $p$ must be the only permitted alternative when it is rational to believe $p$. However, without further principles there might still be permissible alternatives to believing the proposition: namely, not forming any doxastic attitude towards the proposition whatsoever. ${ }^{30}$ This alternative always probably serves the end of avoiding falsity. This is so no matter what the total evidence is. The probability is as high as it can be, 1 . Nothing excludes that this alternative is, in the absence of any further principled considerations, permitted. My position does not exclude nor support that such a permission holds. Epistemic Teleolog $y_{P}^{E A F}$ (together with Avoiding Falsity and Permission) does not exclude that one can be permitted not to believe a proposition even if it would be rational for one to believe the proposition. At the same time Epistemic Teleolog $y_{P}^{E A F}$ also does not support Ought, but is still compatible with it. It is crucial to note, however, that this does not exclude that some further principles - for example, principles that are not teleological in spirit-might be added and so provide support for Ought. The epistemic teleological position here, then, would only partly explain the normativity of rationality: namely, only why it is permitted to believe the proposition for which it is rational to believe it.

Some worries have been raised concerning my position. In the following, I introduce and allay them.

\footnotetext{
30 Note that this alternative does not amount to suspension of judgement, since suspension of judgement involves an attitude with respect to the proposition in question. For appealing accounts that understand suspension of judgement as an attitude see Friedman (2017), Raleigh (2019) and Sturgeon (2019).
} 


\subsection{First worry: skepticism}

One might worry that my position commits me to a skeptical position with respect to contingent propositions. The skeptical worry is that it is never or seldom permitted to believe such propositions. ${ }^{31}$ The reasoning behind the worry is the following: consider the difference between believing a proposition and not forming an attitude towards the proposition. The second alternative does at least as good as the first with respect to the appropriate end of avoiding falsity. The evidential probability of this alternative serving the appropriate end is as high as it can be, 1, and, thus, usually higher than the evidential probability of believing the proposition serving the appropriate end of avoiding falsity. This is worrisome in combination with the idea that it is a necessary condition for permission that there is no alternative that more probably leads to the appropriate end in question; because then not believing a contingent proposition is mostly-if not always - to be preferred. If this line of reasoning were correct, it would indeed leave us with a skeptical position. There are two things to say in reply to proponents of such a worry.

First, what we have said so far does not commit us to a skeptical position. Our Avoiding Falsity and Permission does not commit us to accepting that it is a necessary condition for permission that there is no alternative that more probably leads to the appropriate end in question. As mentioned before, according to Avoiding Falsity and Permission, it is a sufficient condition for being permitted to believe the proposition in question that believing the proposition probably serves the appropriate end of avoiding falsity with respect to it (all given the total evidence). A high evidential probability that believing the proposition in question serves the appropriate end of avoiding falsity (given the total evidence) suffices for permission; the evidential probability does not need to be the highest. We do not need to adopt a skeptical position.

Second, even if one rejected Avoiding Falsity and Permission, the consequence is not as bad as it might seem at first sight. Adopting the skeptical position presented above is not as unattractive as it may seem. Note that the skeptical position would only claim that it is never or seldom epistemically permitted to believe contingent propositions. From a semi-epistemic point of view-that, in addition to epistemic factors, also takes non-epistemic factors into account and endorses the end of inquiry — one can avoid the skeptical result. From such a point of view, which allows for the end of inquiry to be the appropriate end referred to in Epistemic Teleology, one is still semi-epistemically permitted to believe contingent propositions, indeed arguably one even ought to do so. In what follows I explain why.

I am sympathetic to positions that allow for a semi-epistemic value for the end of inquiry. One can argue that the end of inquiry is semi-epistemically valuable due to non-epistemic factors-for instance, because achieving this end helps us to act successfully in general or it fosters the well-being of society in general. This can be so even if not each particular true belief helps in this way. In line with this, one accepts Epistemic Teleology $y_{P}^{E I}$, which helps to explain the semi-epistemic normativity of

\footnotetext{
31 This worry is not to be mistaken with the worry that it is never or seldom rational to believe such propositions. This second worry can be easily dispelled. Given Evidentiali sm $^{S}$, which we assume in this article, it is rational to believe a proposition when the proposition is stably supported by the total evidence. As soon as there is this support, it is rational to believe the proposition.
} 
rationality. Analogous to Avoiding Falsity and Permission, if it is probable that an agent $s$ 's believing a proposition $p$ serves the appropriate end of inquiry with respect to $p$ given $s$ 's total evidence $e_{s}$, then it is permitted that $s$ believes $p$ given $e_{s}$. However, now there is no other alternative that probably serves the end of inquiry with respect to $p$ given the total evidence $e_{s}$. Thus, believing $p$ is the only permitted alternative. A moment's reflection reveals that this is so because if it is probable that an agent $s$ 's believing a proposition $p$ serves the end of inquiry with respect to $p$ given $s$ 's total evidence $e_{s}$, then not believing $p$ does not probably serve the end given $e_{s}$. The following holds:

Inquiry and Ought If an agent $s$ 's believing a proposition $p$ probably serves the appropriate end of inquiry with respect to $p$ given $s$ 's total evidence $e_{s}$, then $s$ ought to believe $p$ given $e_{s}$.

The end of inquiry referred to in Inquiry and Ought is semi-epistemically valuable. In accordance with this the ought referred to in Inquiry and Ought is semi-epistemic as well. Considerations about our individual aims or the well-being of society can save us from the skeptical position that is described above.

\subsection{Second worry: not believing what is rational to believe}

There is another worry. Examples such as the following have been presented as arguments against my position:

Climate-Change Example Climate scientists such as Mary have collected a huge body of evidence that stably supports that there is humaninduced climate change. Given Evidentialism ${ }^{S}$, it is certainly rational for Mary to believe that there is humaninduced climate change. Mary is not just permitted but indeed ought to believe that there is human-induced climate change; her total evidence stably supports that there is human-induced climate change.

One might worry that the example is threatening to my position because my position allows for the case that it can be rational for Mary to believe a proposition and it still be permitted for her not to believe it. In the following, I present three replies that should dispel this worry.

First, as mentioned before, further principles-for example, principles that are not teleological in spirit-might be added to my position. Such can confer support to Ought such that Mary epistemically ought to believe that there is human-induced climate change. I don't see why my position should not be compatible with such an addition. Sure, it does not support Ought, but it is still compatible with it. I am not committed to the position that Ought does not hold, and that one can be permitted not to believe a proposition even if it is rational to believe it. Admittedly, my position does not exclude that there is such a permission, but it is not committed to it either.

Second, one can read 'ought' in different ways, for instance, as an all-thingsconsidered ought, an ethical ought, or-as a referee of this article pointed out to me-an ought that is due to one's professional responsibility. In this example it is 
plausible to read 'ought' in those three ways. One can certainly maintain my position and argue that the climate scientist Mary ought all-things-considered to believe that there is human-induced climate change, argue that Mary ethically ought to believe that, or argue that she ought to believe that in virtue of her role as a scientist. Goldberg (2017) endorses a position that is in line with the latter way of understanding 'ought' in the example above. He discusses an example by Kornblith (1983) that is similar to Climate-Change Example, that deals with a physicist who ignores his colleague's criticism of his position. With respect to this example Goldberg says the following:

So, where $E C$ is the further evidence or considerations his [the physicist's] colleague expressed in her criticisms of his views, and where [p] is the proposition that captures that evidence (and those considerations), we might then say that he should have known that p. Indeed, we might go beyond what Kornblith himself had to say about this case. We might think what the physicist "should have known" is not merely the state of the evidence possessed by his colleague, but also the state of the evidence available to the field more generally, where what is available to the field more generally is itself determined by the prevailing practices within the physics community itself. Where E+ is the state of the evidence available to the field more generally (where this includes, but may not be limited to, the evidence in $E C$ ), and where [p+] is the proposition capturing $\mathrm{E}+$, we might think that the young physicist should have known that $\mathrm{p}+$. The idea is that it is in virtue of his professional responsibilities as a scientist, that we expect the physicist to be aware of the state of the evidence in the field overallas he was under a professional obligation to keep up with the field. (Goldberg 2017, p. 2873).

While I think that a comprehensive account of normativity that concerns what we ought to believe has to engage with various ways of understanding 'ought' and how they are interrelated, I am only concerned with the epistemic normativity (and semi-epistemic normativity) of rationality. Here I have not engaged with all-things-considered normativity, ethical normativity, or the normativity that arises due to one's professional responsibility. My position is silent with respect to these kinds of normativity.

Third, one might still think that there is a sense of epistemic ought according to which Mary is doing something she ought not to do by not believing that there is humaninduced climate change. That one thinks this way can be explained by reference to our everyday talk, where we do not draw a sharp line between epistemic and semi-epistemic normativity. In such talk we do not distinguish the epistemic from the semi-epistemic ought. While one can maintain that Mary is permitted not to believe that there is human-induced climate change in an epistemic sense of 'permission', one can at the same time admit that she ought to believe that there is human-induced climate change in a semi-epistemic sense of 'ought'. One only needs to accept Inquiry and Ought as introduced above. I am happy to accept that in Climate Change Example Mary ought to believe that there is human-induced climate change. Mary semi-epistemically ought to do so. My position, which focuses on epistemic normativity, is compatible with such a view with respect to semi-epistemic normativity. 


\section{Conclusion}

In this article, I started by adopting the following principles:

Evidentialism $^{S}$ It is epistemically rational for an agent $s$ to believe a proposition $p$ given $s$ 's total evidence $e_{s}$ just in case $e_{s}$ stably supports $p$.

Epistemic Teleology If it is epistemically rational for an agent $s$ to believe a proposition $p$ given $s$ 's total evidence $e_{s}$, then $s$ 's believing $p$ adequately serves the appropriate epistemic end given $e_{s}$.

Assuming that rationality is normative - as is common-I investigated the relation between Epistemic Teleology and the following two claims:

Permitted If it is epistemically rational for an agent $s$ to believe a proposition $p$ given $s$ 's total evidence $e_{s}$, then $s$ is epistemically permitted to believe $p$ given $e_{s}$.

Ought If it is epistemically rational for an agent $s$ to believe a proposition $p$ given $s$ 's total evidence $e_{s}$, then $s$ epistemically ought to believe $p$ given $e_{s}$.

The primary aim was to provide an answer to the following question from a standpoint that already takes up Evidentialism ${ }^{S}$ and Epistemic Teleology:

Main Question Does Epistemic Teleology support Permitted or even Ought; and, if so, which?

Before I proposed my answer to the question, I had to review specifications of Epistemic Teleology. I started by considering a specification in terms of the global ratio end (i.e., the end of having a large set of beliefs with the best possible ratio between true and false beliefs). Since such a specification suffered from a trade-off problem, I moved on to investigate a specification that refers to the local end of inquiry instead (i.e., the end of believing a proposition if and only if it is true). An appeal to this end leads to the normativity of rationality being established merely as conditional, stipulated, or semi-epistemic. Hoping for a less restricted account of the normativity, I finally suggested a more radical specification that is in terms of the local end of avoiding falsity (i.e., the end of believing a proposition only if it is true). According to this specification the following holds:

Epistemic Teleology $y_{P}^{E A F}$ If it is rational for an agent $s$ to believe a proposition $p$ given $s$ 's total evidence $e_{s}$, then $s$ 's believing $p$ probably serves the appropriate end of avoiding falsity with respect to $p$ given $e_{s}$.

Adopting and defending Epistemic Teleology $y_{P}^{E A F}$, I went on to answer the Main Question. I answered the question by showing that Epistemic Teleology $y_{P}^{E A}$ supports Permitted but not Ought. As emphazised, my position does not exclude that some further principles might be added and so provide support for Ought. Finally, I dispelled two worries that have been raised against my position. 
Acknowledgements Open Access funding provided by Projekt DEAL. Special thanks go to Wolfgang Barz, Peter Brössel, Thomas Grundmann, Hannes Leitgeb, Stefan Reining, Sebastian Schmidt, Wolfgang Spohn, Ben Young, and two anonymous referees for detailed commentaries on previous versions of the article, which helped me to improve it considerably. I am also grateful to the following for fruitful discussions on the topic: Elke Brendel, Jochen Briesen, Jennifer Carr, Julien Dutan, Catherine Elgin, Branden Fitelson, Joachim Horvath, Christoph Jaeger, Chris Kelp, Thomas Kroedel, Clayton Littlejohn, Kate Nolfi, David Papineau, Thomas Raleigh, Patricia Rich, Pedro Schmechtig, and Miriam Schoenfield. I presented earlier versions of this article at the The Value of Truth Conference in Budapest (which was supported by the MTALendulet Morals and Science Research Project), the workshop Epistemic Consequentialism in Konstanz, the conference of the European Epistemology Network in Paris, the conference Epistemic Rationality: Conceptions and Challenges in Barcelona, the workshop on Knowing - Understanding - Explaining in Dresden, and at a departmental colloquium at the University of Hamburg. I would like to thank the audiences of these events for constructive commentaries. I also discussed a former version of the article in a research seminar led by Thomas Spitzley at the University of Duisburg-Essen and in a research seminar led by Erasmus Mayr at the University of Erlangen-Nuremberg. I am grateful to the participants of the seminar for helpful remarks.

Open Access This article is licensed under a Creative Commons Attribution 4.0 International License, which permits use, sharing, adaptation, distribution and reproduction in any medium or format, as long as you give appropriate credit to the original author(s) and the source, provide a link to the Creative Commons licence, and indicate if changes were made. The images or other third party material in this article are included in the article's Creative Commons licence, unless indicated otherwise in a credit line to the material. If material is not included in the article's Creative Commons licence and your intended use is not permitted by statutory regulation or exceeds the permitted use, you will need to obtain permission directly from the copyright holder. To view a copy of this licence, visit http://creativecommons.org/licenses/by/4.0/.

\section{References}

Ahlstrom-Vij, K., \& Dunn, J. (2014). A defence of epistemic consequentialism. Philosophical Quarterly, $64,541-551$.

Berker, S. (2013). The rejection of epistemic consequentialism. Philosophical Issues, 23, 363-387.

Berker, S. (2015). Reply to Goldman: Cutting up the one to save the five in epistemology. Episteme, 12, 145-153.

Brössel, P. (2012). Rethinking Bayesian confirmation theory. Ph.D. thesis, University of Konstanz.

Brössel, P., \& Eder, A. M. A. (2014). How to resolve doxastic disagreement. Synthese, 191, 2359-2381.

Brössel, P., Eder, A. M. A., \& Huber, F. (2013). Evidential support and instrumental rationality. Philosophy and Phenomenological Research, 87, 279-300.

Christensen, D. (2004). Putting logic in its place. Oxford: Oxford University Press.

Cohen, S. (2016). Theorizing about the epistemic. Inquiry: An Interdisciplinary Journal of Philosophy, 59, $839-857$.

Conee, E. (1994). Against an epistemic dilemma. Australasian Journal of Philosophy, 72, 475-481.

David, M. (2014). Truth as the primary epistemic goal: A working hypothesis. In M. Steup, J. Turri, \& E. Sosa (Eds.), Contemporary debates in epistemology (pp. 363-377). Oxford: Oxford University Press.

Douven, I. (2008). The lottery paradox and our epistemic goal. Pacific Philosophical Quarterly, 89, 204225.

Eder, A. M. A. (2019). Evidential probabilities and credences. The British Journal for the Philosophy of Science. https://doi.org/10.1093/bjps/axz043.

Firth, R. (1981). Epistemic merit, intrinsic and instrumental. Proceedings and Addresses of the American Philosophical Association, 55, 5-23.

Friedman, J. (2017). Why suspend judging? Noûs, 2, 302-326.

Fumerton, R. (2001). Epistemic justification and normativity. In M. Steup (Ed.), Knowledge, truth, and duty: Essays on epistemic justification, responsibility, and virtue (pp. 49-61). Oxford: Oxford University Press.

Goldberg, S. (2017). Should have known. Synthese, 194, 2863-2894.

Goldman, A. (2015). Reliabilism, veritism, and epistemic consequentialism. Episteme, 12, 131-143. 
Goldman, A., \& Olsson, E. J. (2009). Reliabilism and the value of knowledge. In A. Haddock, A. Millar, \& D. Pritchard (Eds.), Epistemic value (pp. 19-41). Oxford: Oxford University Press.

Grimm, S. R. (2009). Epistemic normativity. In A. Haddock, A. Millar, \& D. Pritchard (Eds.), Epistemic value (pp. 243-264). Oxford: Oxford University Press.

Kelly, T. (2003). Epistemic rationality as instrumental rationality: A critique. Philosophy and Phenomenological Research, 66, 612-640.

Kelly, T. (2007). Evidence and normativity: Reply to Leite. Philosophy and Phenomenological Research, $75,465-474$.

Kornblith, H. (1983). Justified belief and epistemically responsible action. The Philosophical Review, 92, $33-48$.

Kornblith, H. (1993). Epistemic normativity. Synthese, 94, 357-376.

Levi, I. (1974). On indeterminate probabilities. Journal of Philosophy, 71, 391-418.

Levi, I. (1980). The enterprise of knowledge. Cambridge: MIT Press.

Maher, P. (2006). The concept of inductive probability. Erkenntnis, 65, 185-206.

Maitzen, S. (1995). Our errant epistemic aim. Philosophy and Phenomenological Research, 55, 869-876.

Nelson, M. (2010). We have no positive epistemic duties. Mind, 119, 83-102.

Nozick, R. (1993). The nature of rationality. Princeton: Princeton University Press.

Odegard, D. (1993). Resolving epistemic dilemmas. Australasian Journal of Philosophy, 71, 161-168.

Papineau, D. (2013). There are no norms of belief. In T. Chan (Ed.), The aim of belief (pp. 64-79). Oxford: Oxford University Press.

Raleigh, T. (2019). Suspending is believing. Synthese. https://doi.org/10.1007/s11229-019-02223-8.

Smithies, D. (2015). Ideal rationality and logical omniscience. Synthese, 192, 2769-2793.

Smithies, D. (2016). Belief and self-knowledge: Lessons from Moore's paradox. Philosophical Issue, 26, $393-491$.

Sosa, E. (2007). A virtue epistemology: Apt belief and reflective knowledge. Oxford: Oxford University Press.

Steglich-Petersen, A. (2011). How to be a teleologist about epistemic reasons. In A. Steglich-Petersen \& A. Reisner (Eds.), Reasons for belief (pp. 13-33). Cambridge: Cambridge University Press.

Sturgeon, S. (2019). Epistemic attitudes. Oxford: Oxford University Press.

Wedgwood, R. (2002). The aim of belief. Philosophical Perspectives, 36, 267-297.

Williamson, T. (2000). Knowledge and its limits. Oxford: Oxford University Press.

Williamson, T. (2017). Ambiguous rationality. Episteme, 14, 263-274.

Publisher's Note Springer Nature remains neutral with regard to jurisdictional claims in published maps and institutional affiliations. 